\title{
As limitações da linguagem no ensino da Mecânica Quântica
}

A

DISCIPLINA “ESTRUTURA ATÓMICA E MOECULAR" integra o elenco de disciplinas obrigatórias do $2{ }^{\circ}$ ano da licenciatura em Química, e nasceu da reestruturação do seu plano curricular que o Departamento de Química da Faculdade de Ciências da Universidade do Porto levou a cabo nestes últimos quatro anos. Pretende-se com esta disciplina, que comporta um considerável legado das semestrais "Introdução à Mecânica Quântica" e "Química Teórica" do antigo $3 .^{\circ}$ ano da licenciatura, proporcionar ao aluno conhecimentos de base sólidos sobre a estrutura da matéria que, apresentados mais cedo na sua vida académica, facilitar-Ihe-ão, com certeza, a compreensāo e aprofundamento de outros assuntos da química. A motivação para a escrita deste texto surgiu da rica experiência pedagógica de preparação e regência dos primeiros três anos de vida desta disciplina. O contacto directo com os alunos permitiu aperceber-me das dificuldades mais comuns por eles sentidas, especialmente por aqueles que desejam enveredar por uma química experimental mais aplicada.

No programa desta disciplina começase por fazer uma sucinta retrospectiva histórica da Física Clássica dos finais do século XIX, referindo as dificuldades que ela enfrentou para explicar e prever alguns fenómenos físicos, e o aparecimento e consolidação da Mecânica Quântica como linguagem nova que acabou por se impor como única alternativa para o estudo da Natureza à es- cala sub-molecular. Os postulados e metodologia da Mecânica Quântica vão sendo introduzidos ao nivel de um curso geral de Química-Física, apresentandose posteriormente alguns modelos teóricos simples, usados para interpretar a estrutura electrónica de átomos e moléculas. As características roto-vibracionais das moléculas e sua relação com dados experimentais de espectroscopia são também estudadas à luz da Mecânica Quântica. Por fim, apresenta-se ao aluno um panorama geral dos tipos de metodologias teóricas de que um químico dispõe hoje em dia para estudar computacionalmente as caracteristicas fisico-químicas de um sistema molecular. Estes conceitos teóricos são complementados nas aulas práticas com a realização de trabalhos com montagem laboratorial sobre, por exemplo, o efeito fotoeléctrico e espectroscopia de emissão atómica, e de trabalhos computacionais, entre os quais se destacam aplicações concretas do modelo da partícula na caixa, do método de Hückel simples e do modelo do oscilador harmónico.

0 tratamento matemático utilizado na abordagem introdutória dos fundamentos da Mecânica Quântica não me pareceu suscitar grande desconforto nos alunos. Porém, os resultados numéricos que daí emergem, e o choque que eles geram com a intuição empírica do mundo, criam sentimentos de estranheza, de curiosidade e, por vezes, até espontâneas reacções de negação. É natural que a desconfiança e repulsa nos assalte com tal intensidade quando contactamos pela primeira vez com conceitos de índole quântica tão distantes da realidade física do dia a dia. Sempre considerei salutar este tipo de reacção na sala de aula, pois revela espírito crítico e maturidade intelectual por parte dos alunos que, para além de quererem dominar a mecânica de resolução dos problemas apresentados, mostram também interesse pelas implicações a nivel do entendimento e concepção do mundo que a Ciência vai construindo. Bohr costumava dizer que "Quem não se sente chocado com a Mecânica Quântica é porque não a entendeu".

Sabemos como a Mecânica Quântica tem tido dificuldades de aceitação, mesmo no seio da comunidade científica da especialidade, apesar dos seus irrefutáveis sucessos na previsão quantitativa de fenómenos nunca explicados pela Física Clássica. Desde o proverbial duelo científico/filosófico travado entre Bohr e Einstein no segundo quartel do século XX, esta teoria tem resistido até hoje a todo o tipo de provas de fogo a que a sujeitaram desde então ${ }^{1}$. 0 choque epistemológico que ela constitui teve como primeira manifestação a revolucionária hipótese da quantificação energética que Max Planck propôs num célebre artigo $^{2}$ de 1900 para descrever correctamente a distribuição de frequências da radiação emitida por sólidos em equilíbrio térmico. Os extraordinários avanços que a Física Clássica alcançara nos finais do século XIX, especialmente no campo do Electromag-

* Departamento de Química da Faculdade de Ciências da Universidade do Porto, R. Campo Alegre, 687 - 4169-007 Porto

Centro de Química da Universidade do Porto/REQUIMTE , Endereço electrónico: almagalh@fc.up.pt 
netismo e Fisica Estatística, criaram a confortável mas perigosa ilusão de que um estado de conhecimento pleno havia sido atingido, e que os poucos fenómenos que ainda careciam de explicação constituíam "apenas" últimos detalhes a serem resolvidos. A Mecânica Quântica, fundamentada por um edifício matemático rigoroso, explica com sucesso, entre outras coisas, a estabilidade dos átomos, a interacção entre eles na formação das moléculas ou as caracteristicas da luz que podem emitir. Porém, este brilhante desempenho é conseguido à custa do sacrifício de princípios como objectividade e determinismo, verdadeiros pilares da Ciência e pensamento da Idade Moderna, que se caracterizaram pela "crença" de uma racionalidade absoluta do Real e da possibilidade de o pensamento humano atingir absolutamente essa racionalidade do Mundo. Não espanta, pois, que a teoria quântica que emergiu no dealbar do século seguinte tenha sido encarada como uma afronta ao sólido edifício do pensamento científico vigente, apesar de se revelar "estranhamente" correcta. Mesmo alguns dos ilustres vultos que contribuíram para a construçẫo e consolidação deste novo formalismo ao longo das duas décadas seguintes, como Einstein e De Broglie, mostraram uma repulsa irredutível pelas revolucionárias consequências filosóficas e de concepção da realidade que naturalmente daí resultam. Ao fim de quase um século de existência, a Mecânica Quântica permanece uma teoria polémica e difícil de interiorizar, tal é o conflito entre os seus pressupostos e a realidade física do nosso quotidiano macroscópico.

Alunos que frequentam a Universidade há um ano estão, obviamente, longe de possuírem a maturidade científica e filosófica de tão brilhantes personalidades da Ciência do século XX. Como iniciálos, então, nesta "nova" teoria sem que isso Ihes pareça uma imposição violenta de uma matéria de estudo sem aplicação prática, uma inutilidade matemática, um obstáculo sem sentido ao sucesso na disciplina? Penso que, num curso desta natureza e com aproximadamente $40 \mathrm{~h}$ horas teóricas, mais importante do que exigir o entendimento da Mecânica Quântica será habituarmo-nos aos seus resultados e irrefutáveis sucessos, através do estudo de propriedades macroscópicas e técnicas experimentais que se baseiam em fenómenos quânticos tão bem escondidos dos nossos sentidos no mundo muito próprio da escala atómica. Esta atitude pode ajudar a estimular a curiosidade científica e a vencer o preconceito para com realidades que são imperceptiveis à nossa escala biológica mas que são previstas pela teoria mais abrangente que hoje possuímos para representar a realidade física da matéria. De facto, as explicações e imagens simples, que são as ferramentas tradicionais da pedagogia, tornam-se insuficientes para descrever esses fenómenos, podendo inclusive atraiçoar a própria teoria quântica, porque a linguagem por nós utilizada foi desenvolvida para lidar com objectos e acontecimentos da vida corrente, onde não há paralelo para os efeitos quânticos que ocorrem à escala atómica. Sabemos que um electrão, ou outra partícula qualquer, pode manifestar-se como onda ou como corpúsculo, mas nenhuma experiência permite detectar simultaneamente estas duas manifestações da sua natureza. No entanto, continua a ser necessário utilizar este tipo de linguagem para descrever os resultados experimentais, apesar de sabermos que um electrāo não possui natureza corpuscular ou ondulatória puras. Então, qual é a verdadeira essência do electrão independentemente da experiência utilizada para o estudar? Bohr, que cedo reconheceu a importância da problemática da linguagem, avança com o conceito de complementaridade, falando-se então numa dualidade onda-corpúsculo, que será sempre uma característica dificil de interiorizar para quem vive no mundo macroscópico. Os trabalhos de Bohr e de Heisenberg lançaram a base da Interpretação de Copenhaga da teoria quântica segundo a qual a realidade é estatística e não exacta, e que o mundo deve ser realmente observado para ser objectivo, sendo certo que o processo de observação influencia o fenómeno a estudar, ou seja, a intencionalidade humana influencia a estrutura do mundo físico. A Mecânica Quântica abandona, assim, a tendência que as Ciências exactas tinham até então de tentar encontrar as relações causais escondidas na própria natureza dos fenómenos e apresenta uma postura mais pragmática de previsão de resultados experimentais. Bohr chega a concluir que "É errado pensar que a tarefa da Fisica é descobrir o que a natureza é. A Física ocupa-se daquilo que podemos dizer sobre a natureza" ${ }^{3}$.

Perante conclusões tão desconcertantes, parece-me pedagogicamente mais enriquecedor para alunos principiantes começar por transmitir o sucesso da Mecânica Quântica na explicação de fenómenos como, por exemplo, o decaimento radioactivo, a estrutura quantificada dos espectros atómicos, ou a inversão de uma molécula piramidal como a do amoníaco. Mostrar-Ihes que a aplicação de fenómenos puramente quânticos estiveram na base de conquistas tecnológicas como a invenção do microscópio de varrimento por efeito de túnel (ou do maser - microwave amplified by stimulated electronic ressonance, percursor do laser) parece-me também muito importante para acreditar a Mecânica Quântica junto a uma audiência naturalmente incrédula.

Outras estratégias didácticas podem ser seguidas para ajudar $\mathrm{o}$ aluno a familiarizar-se com esta diferente realidade, recorrendo, por exemplo, a software educativo o mais interactivo possivel. 0 modelo da partícula na caixa constitui um excelente paradigma para a introdução de conceitos de natureza quântica tão pouco intuitivos como, por exemplo, o da quantificação da energia, a energia do ponto zero ou o efeito de túnel. Será raro o autor de um livro didáctico de introdução à mecânica quântica que resista ao encanto pedagógico deste modelo teórico tão simples e versátil. De facto, ele tem-se revelado de grande utilidade para o aluno por ser de concepção suficientemente acessivel e permitir-Ihe uma aplicação imediata do formalismo quântico sem recorrer a ferramentas matemáticas complexas. A resolução da equação de Schrödinger para casos simples de poços de poten- 
cial permite ao aluno um primeiro contacto com a validação matemática de conceitos de natureza puramente quântica que, eventualmente, já Ihe tenham sido apresentados anteriormente de uma forma obviamente forçada e qualitativa. Este modelo reúne, portanto, características suficientes para se justificar um investimento na preparação de aplicações informáticas de índole didáctica. Existem versões antigas que serviram durante muito tempo o propósito pedagógico para o qual foram desenvolvidas e, actualmente, podem ser encontrados na Internet algumas aplicações com visualização gráfica de resultados que, no entanto, pecam pela reduzida interactividade com o utilizador e/ou pela pouca variedade de resultados e de escolha de parâmetros iniciais ${ }^{5}$. Parece-me oportuno, neste momento, explorar as novas potencialidades gráficas e de processamento que os computadores pessoais apresentam hoje em dia para conceber versões satisfatoriamente interactivas e apelativas, desenvolvidas numa linguagem de programação acessível. Um projecto desta natureza, proposto como trabalho de conclusão de licenciatura a um aluno de Química, pode proporcionar um diálogo privilegiado entre professor e aluno, e uma troca de experiências e sensibilidades aos problemas da Mecânica Quântica tão proveitoso para ambos, que ajudará, sem dúvida, a conceber uma aplicação informática de boa qualidade pedagógica destinada directamente ao aluno principiante.

\section{Referências}

${ }^{1}$ a) J.Baggott, (1990) J. Chem. Educ. 67, 8, 638-642 ; b) F. Selleri, Paradoxos e Realidade- Ensaios Sobre os Fundamentos da Microfisica, Editorial Fragmentos, Lda, Lisboa, 1990 ; c) E.Klein, La Physique Quantique,
Flammarion, 1996 ; d) H.C. von Baeyer, Taming The Atom-The Emergence of the Visible Microworld, Dover Publications, Inc., Mineola,New York, 1992

${ }^{2}$ M.Planck, (1900) Verh. Deut. Phys. Ges. 2. 237-245

${ }^{3}$ a) Heinz R. Pagels, O Código Cósmico, a Fisica Quântica como Linguagem da Natureza, Gradiva, Lisboa, 1982 ; b) Werner Heisenberg, Diálogos sobre Física Atómica, Editorial Verbo, Lisboa, 1975

${ }^{4}$ Magalhães,A. e J.A.N.Ferreira Gomes, (1990), Boletim da Sociedade Portuguesa de Química 41, 23

${ }^{5}$ http://www.chem.uci.edu/education/undergrad_pgm/applets/dwell/dwell.htm

http://psheldon.rmwc.edu/hnguyen/ particle.htm

http://artemis1.physics.uoi.gr/ rizos/diplomatikes/pappas_j/quantum/enqindex.html

http://ir.chem.cmu.edu/irproject/applets/color /Applet.asp

http://library.wolfram.com/webMathematica/MSP/Explore/Physics/Quantum

\section{re

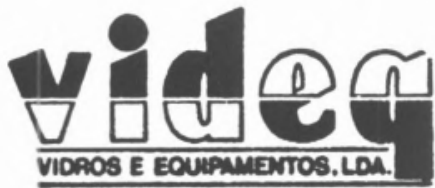

Equipamento de Laboratório

Balanças - Centrifugas - Aparelhos de $\mathrm{pH}$ - Tituladores

Condutímetros - Agitadores - Espectrofotómetros

Microscópios - etc.

\section{Vidros e Plásticos de Laboratório Distribuidores NORMAX}

Material Didáctico

Ensino Secundário e Superior

Representantes exclusivos SISTEDUC - Sistemas Educativos S.A.

Rua Soeiro Pereira Gomes, 15 r/c Frente

Bom Sucesso - 2615 Alverca

Telefs. (01) 95704 20/1/2 - Fax (351-1-957 04 23) - Portugal 